\title{
Prediction of Stream Flow and Sediment Yield of Lolab Watershed Using SWAT Model
}

\section{Sarvat Gull, Ahangar MA and Ayaz Mohmood Dar*}

Department of Civil Engineering, National Institute of Technology, Srinagar, Jammu and Kashmir, India

\begin{abstract}
The SWAT model was used to estimate the runoff and sediment yield of Lolab watershed. The model was calibrated, validated, and assessed for evaluation to model ambiguity using Nash-Sutcliffe coefficient $\left(\mathrm{N}_{\mathrm{SE}}\right)$ and coefficient of determination $\left(\mathrm{R}^{2}\right)$. Ten highly sensitive parameters were recognized for stream flow simulation of which CN2 (Initial SCS CN II value) factor was the most sensitive one and four highly sensitive parameters were recognized for sediment yield simulation of which SPCON (Linear parameters for sediment re-entrainment) was most sensitive one. The model was calibrated for a time period between 1993 to 2000 and validated from 2001 to 2004 for flow and sediment yield. The predicted and observed stream flow and sediment yields generally matched well. The results of the model calibration and validation showed reliable estimates of monthly stream flow $\left(R^{2}=0.74\right.$ and $\left.E_{N S}=0.68\right)$ and yearly stream flow $\left(R^{2}=0.90\right.$ and $\left.E_{N S}=0.68\right)$ during the calibration period and monthly stream-flow $\left(R^{2}=0.85\right.$ and $\left.E_{N S}=0.83\right)$ and yearly stream-flow $\left(R^{2}=0.99\right.$ and $\left.E_{N S}=0.91\right)$ during the validation period. For sediment yield, this study shows antremendous model efficiency of monthly sediment yield $\left(R^{2}=0.80\right.$ and $\left.E_{N S}=0.79\right)$ and yearly sediment yield $\left(R^{2}=0.86\right.$ and $\left.E_{N S}=0.78\right)$ during the calibration period and monthly sediment yield $\left(R^{2}=0.88\right.$ and $\left.E_{N S}=0.86\right)$ and yearly sediment yield $\left(R^{2}=0.83\right.$ and $\left.E_{N S}=0.58\right)$ during the validation period. This study showed that the SWAT model is competent of predicting sediment yields and hence can be used as a tool for water resources planning and management in the study watershed.
\end{abstract}

Keywords: SWAT model; Model evaluation; Stream flow; Sediment yield

\section{Introduction}

A Watershed is an area of land that drains all the streams and rainfall to a common outlet. Essentially a watershed is all the land and water area which contributes runoff to an outlet in the main flow channel [1]. Watersheds are significant because the stream flow and the water quality of a river are affected, human-induced or natural, happening in the land area "above" the river-outflow point. The environment worsening of a watershed is a common occurrence in most parts of the world. Amongst several causes the major one are improper and unwise utilization of watershed resources observed in developing countries [2]. Watershed management implies rational utilization of land, soil, and water resources for optimum and sustained production with minimum hazards to natural resources and environment [3]. Soil erosion is a serious global issue because of its rigorous adverse economic and environmental impacts. Economic impacts on productivity may be due to direct effects on crops/plants both on-site and off-site, and environmental consequences are primarily off-site related to the damage to civil structure, siltation of water ways and reservoirs, and additional costs involved in water treatment. Even though the adverse influences of soil erosion on soil degradation have long been recognized as a key problem for human sustainability, estimation of soil erosion is often complicated due to the complex interplay of many factors such as climate, land cover, soil, topography, lithology, and human activities. This study employs the SWAT (Soil and Water Assessment Tool) model to take advantage of its integration with GIS (Geographic Information System) and locally available data and data from similar areas that can be used to calibrate and validate the model, so that runoff and sediment yield from the watershed can be predicted and most problematic sub-basins can be identified.

\section{Objectives of the Study}

1) To analyze the Land use/Land cover of Lolab watershed.
2) To estimate the catchment runoff and sediment yield of Lolab watershed of Pohru catchment using SWAT model.

3) To evaluate the performance of Swat model by comparing its predicted flow and sediment yield with corresponding observed values at the study watershed.

4) To identify the most problematic sub-basins with respect to sediment contribution.

\section{Methods and Materials}

Lolab watershed is one of the watersheds of Pohru catchment with an area of about 45,250 hectares. The study area lies between $34^{\circ} 41^{\prime}$ to $34^{\circ} 24^{\prime} \mathrm{N}$ Latitude and $74^{\circ} 09^{\prime}$ to $74^{\circ} 23^{\prime}$ E Longitude. The watershed can be divided into three distinct physiographic units i.e., the Mountains, the Karewas and the Flood plains. Elevation in the watershed varies from approximately 1,500 to 3,900 meters above mean sea level.

\section{Model description}

Arc SWAT: ArcSWAT is a public domain graphical user interface program. It is designed to link the hydrologic model SWAT (Soil and Water Assessment Tool) and the GIS package ARCINFO. The SWAT model is limited in that it does not explicitly allow for the inclusion of spatial data as model inputs. Data must be processed into a form

*Corresponding author: Ayaz Mohmood Dar, Department of Civil Engineering, National Institute of Technology, Srinagar, Jammu and Kashmir, India, Tel: +919797264162; E-mail: ayazmohmood@hotmail.com

Received January 09, 2017; Accepted January 17, 2017; Published January 24 2017

Citation: Gull S, Ahangar MA, Dar AM (2017) Prediction of Stream Flow and Sediment Yield of Lolab Watershed Using SWAT Model. Hydrol Current Res 8: 265. doi: 10.4172/2157-7587.1000265

Copyright: (c) 2017 Gull S, et al. This is an open-access article distributed under the terms of the Creative Commons Attribution License, which permits unrestricted use, distribution, and reproduction in any medium, provided the original author and source are credited. 
that the model can use. Processing these data, even with the use of a GIS is tiresome and time consuming due to the large number of model parameters required for executing SWAT. The development of ArcSWAT aims at an effective use of spatial data to enhance hydrological modeling. The interface performs the following tasks

- To streamline GIS processes tailored toward SWAT modeling needs.

- To automate data communication between Arc/Info and SWAT.

- To provide a user-friendly data entry and editing environment for SWAT.

The SWAT model: The Soil and Water Assessment Tool (SWAT) is a river basin scale, continuous time and spatially distributed physically based model developed to predict the impact of land management practices on water, sediment, and agricultural chemical yields in complex catchments with varying soils, land use and management conditions over long periods of time [4,5]. In this study, the Arc SWAT 2005 version of the SWAT model is applied to predict stream flow and sediment yield. SWAT uses Hydrologic Response Units (HRUs) to describe spatial heterogeneity in terms of land cover, soil type and slope within a catchment. The SWAT model uses two steps for the simulation of hydrology: the land phase and routing phase. The land phase controls the amount of sediment, nutrient and pesticides loading to the main channel in each sub-basin. SWAT offers two methods for estimating surface runoff: The Soil Conservation Service (SCS) Curve Number $(\mathrm{CN})$ procedure and the Green and Ampt infiltration method. Using daily or sub-daily rainfall amounts, SWAT simulates surface runoff volumes and peak runoff rates for each HRU. SCS curve number method is less data intensive than the Green-Ampt method [6]. In this study, the SCS curve number method was used to estimate surface runoff volumes because of the unavailability of sub-daily data for the Green and Ampt method. Sediment yield is estimated using a Modified Universal Soil Loss Equation (MUSLE).

\section{Preparation of model inputs}

The basic spatial input datasets used by the model include the Digital Elevation Model (DEM), stream network, land use/cover data, soil data and climatic data. DEM was derived from the NASA 15-meter Shutter Radar Topography Mission (SRTM) dataset. The DEM was used to delineate the catchment and analyze the drainage patterns of the land surface as well as derive slope parameter. The stream network data set was digitized from topographic map of scale (1:50000 and 1:250000) of the study area. The stream network dataset was superimposed onto the DEM to define the location of the stream network. Burning-in stream network operation is most important in situations where the DEM does not provide enough detail to allow the interface to accurately predict the location of the stream network. The land use is one of the most important factors that affect runoff, evapotranspiration, and surface erosion in a watershed. The land use map was obtained from the Department of Agricultural Engineering, SKUAST-K. Agriculture was the dominant land use category in the Lolab watershed followed by the sparse forest.

Since SWAT has pre-defined land use types which identified by four-letter codes, the Land use/Land cover map was reclassified in order to correspond with the parameters in the SWAT database.

The SWAT model requires different soil textural and physicalchemical properties such as soil texture, available water content, hydraulic conductivity, bulk density, and organic carbon content for different layers of soil. In this particular study, Soil Conservation Department, Kashmir global available soil data (1:50,00,000 scales) in vector format had been obtained from Earth Science Department, Kashmir University. It is converted into a grid format for SWAT model input parameters. A total of three soil texture classes were delineated out of which the fine loamy soil was the major class which accounted for 79.58 percent of the total area of the watershed and was followed by fine silty soil with 16.53 percent of the total area.

Meteorological data is needed by the SWAT model to simulate the hydrological conditions of the basin. The meteorological data required for this study were obtained from Indian Meteorological Department. The meteorological data collected were precipitation, maximum and minimum temperature, wind speed and sunshine hours. The records between 1993 and 2004 were obtained. The problem in the weather data was inconsistency in the data record, in some periods there is a record for precipitation but temperature data are missing, and vice versa. The hydrological data was required for performing sensitivity analysis, calibration, and validation of the model. The hydrological data was collected from Irrigation and Flood Control Department, Kashmir. Sediment data was obtained from Soil and Water Conservation Department, Jammu and Kashmir.

\section{Arc SWAT model setup}

The ArcSWAT interface was used for the setup and parameterization of the model. Digital Elevation Model was imported into the SWAT model to automatically delineate the watershed into several hydrologically connected sub-watersheds. After the DEM grid was loaded and the stream networks superimposed, the DEM map grid was processed to remove the non-draining zones. The initial stream network and sub-basin outlets were defined based on drainage area threshold approach. Besides those sub-basin outlets created by the interface, outlets were also manually added at the gauging stations where sensitivity analysis, calibration and validation tasks were later performed. Then watershed delineation activity was finalized by calculating the geomorphic sub-basin parameter. A total of 43 sub basins were created.

The land use and the soil data in a projected Grid file format were loaded into the Arc SWAT interface to determine the area and hydrologic parameters of each land-soil category simulated within each sub-watershed. The DEM data used during the watershed delineation was also used for slope classification. The multiple slope discretization operation was preferred over the single slope discretization as the sub-basins have a wide range of slopes between them. Based on the suggested minimum, maximum, mean and median slope statistics of the watershed, three slope classes $(0-10,10-20$, and $>20)$ were applied and slope grids reclassified. Then land use, soil and slope grids were overlaid. In multiple HRU definition, a threshold level was used to eliminate minor land uses, soils, or slope classes in each sub-basin. Land uses, soils or slope classes which cover less than the threshold level was eliminated and the area of the remaining land use, soil, or slope class was reapportioned so that $100 \%$ of the land area in the subbasin was modeled. The threshold levels set is a function of the project goal and amount of detail required. In the SWAT user manual, it is suggested that it is better to use a larger number of sub-basins than larger number of HRUs in a sub-basin; a maximum of 10 HRUs in a sub-basin is recommended. Hence, taking the recommendations into consideration, $5 \%, 5 \%$, and $5 \%$ threshold levels for the land use, soil and slope classes were applied, respectively so as to encompass most of spatial details. A total of 244 HRU's were created. The climatic variables required by SWAT daily precipitation, maximum and minimum 
temperature, solar radiation, wind speed and relative humidity were prepared in the appropriate dbase format and imported into the model.

SWAT is a complex model with many parameters that makes manual calibration difficult. Hence, sensitivity analysis was performed to limit the number of optimized parameters to obtain a good fit between the simulated and measured data. Sensitivity analysis helps to determine the relative ranking of which parameters most affect the output variance due to input variability [7] which reduces uncertainty and provides parameter estimation guidance for the calibration step of the model. SWAT model has an embedded tool to perform sensitivity analysis and provides recommended ranges of parameter changes. SWAT2005 uses a combination of Latine Hypercube Sampling and One-At-a-Time sensitivity analysis methods (LH-OAT method) [8]. The concept of the Latin-Hypercube Simulation is based on the Monte Carlo Simulation to allow a robust analysis but uses a stratified sampling approach that allows efficient estimation of the output statistics while the One-Factor-At-a-Time is an integration of a local to a global sensitivity method [8]. In local methods, each run has only one parameter changed per simulation which aides in the clarity of a change in outputs related directly to the change in the parameter altered [8].

\section{Model calibration and validation}

There are three calibration approaches widely used by the scientific community. These are the manual calibration, automatic calibration, and a combination of the two. Manual calibration is the most widely used approach. However, it is tedious, time consuming, and success of it depends on the experience of the modeler and knowledge of the watershed being modeled [9]. Automatic calibration involves the use of a search algorithm to determine best-fit parameters. It is desirable as it is less subjective and due to extensive search of parameter possibilities can give results better than if done manually.

The manual calibration approach helps to compare the measured and simulated values, and then to use the expert judgment to determine which variable to adjust, how much to adjust them, and ultimately assess when reasonable results have been obtained. The auto- calibration technique is used to obtain an optimal fit of process parameters which is based on a multi-objective calibration and incorporates the Shuffled Complex Evolution Method algorithms [8]. The model was calibrated in order to make the simulation result more realistic for independent calibration period (1993 to 2000). In this study, both the manual and auto-calibration techniques were employed to get the best model parameters.

In order to utilize the calibrated model for estimating the effectiveness of future potential management practices, the model was tested against an independent set of measured data. This testing of a model on an independent set of data set was used. As the model, predictive capability was demonstrated as being reasonable in both the calibration and validation phases, the model can be used for future predictions under different management scenarios. In this study, the model was validated with independent validation period (2001-2004). The simulation flowchart is shown in Figure 1.

\section{Results and Discussion}

\section{Sensitivity analysis and parameters calibration}

The first simulation using default parameters was not able to correctly reproduce the runoff in the watershed because the actual discharge peaks were underestimated and the base flow was overestimated. Therefore, parameters calibration was need after identifying the most sensitive parameters for runoff shown in Table 1.
The $\mathrm{CN} 2$ was increased by $7 \%$ of the original value to increase the runoff and decrease infiltration. SOL_AWC was reduced by $20 \%$ in all soils to increase the movement of water within the soil profiles. The default value of SOL_K for the soil profiles resulted in an overestimation of the lateral flow in the watershed; therefore, the SOL_K was decreased by $13 \%$ to reduce the lateral flow in the soil profiles. SLSUBBSN was also used to control the estimates of lateral flow, and the calibrated values were varied from 25 to $228 \mathrm{~m}$ for the individual sub-basins. The simulated runoff become closer to the observed runoff when the ESCO was adjusted to 0.15 and the EPCO was adjusted to 0.38 because these changes allow us to modify the depth distribution of water in the soil layers to meet soil evaporation and plant uptake demands. The default value of ALPHA_BF leaded to large base flow; however, the Lolab watershed has a characteristically rapid response of runoff to rainfall, and the watershed has zero or a low base discharge during dry seasons. Therefore, adjusting ALPHA_BF to 0.70 caused the simulated discharge recession curve to be steeper than when using the default value, which represents the faster drainage behavior of the watershed. GWQMN and GW_REVAP affect the amount of groundwater flow and control the upwelling of groundwater into the unsaturated soil zone. The effects of these parameters on base flow also affect runoff, and low values of GWQMN correspond to high runoff [10]; thus, this parameter was adjusted to 37 to realistically predict daily runoff. In addition, SOL_Z and $\mathrm{CH}$ _K2 were determined to be $2,400 \mathrm{~mm}$ and $31 \mathrm{~mm} \mathrm{~h}-1$ to obtain better model accuracy. Table 2 presents an overview of the parameter changes applied during sediment calibration. The parameters were modified based on appropriate ranges as defined in the SWAT model documentation. The values of SPCON and SPEXP were adjusted to increase channel sediment transport capacity and lower the amount of sediment deposition. Two other sensitive parameters affecting sediment transport at the watershed level, $\mathrm{CH}$ _EROD and $\mathrm{CH}$ _COV, were adjusted to 0.55 and 0.30 respectively (Table 2).

\section{Evaluation of stream flow simulation}

The observed and simulated monthly and yearly stream flow for the calibration period from 1993-2000 are shown in Figures 2 and 3. The statistical results for the model performance displayed satisfactory efficiency with $\mathrm{R}^{2}=0.74$ and $\mathrm{N}_{\mathrm{SE}}=0.68$ for monthly stream flow and $\mathrm{R}^{2}=0.90$ and $\mathrm{N}_{\mathrm{SE}}=0.68$ for annual flows between the simulated and observed data shown in Table 3. However, the simulated flow was generally lower than the corresponding observed values during periods with concentrated rainfall. The calibrated model was then run from 2001 2004 to validate the model. The observed and simulated monthly and yearly stream flow for the validation period from 2001-2004 are shown in Figures 4 and 5. The statistical analysis results also demonstrated reasonable agreement between the observed and simulated stream flow with monthly $\mathrm{R}^{2}$ value of 0.85 and $\mathrm{N}_{\mathrm{SE}}$ value of 0.83 and yearly $\mathrm{R}^{2}$ value of 0.99 and $\mathrm{N}_{\mathrm{SE}}$ value of 0.91 . Although the statistical evaluation showed the satisfactory stream flow simulation for both calibration and validation periods, SWAT tended to underestimate the runoff during high-flow periods. This could be partly because the present curve number technique is unable to generate accurate runoff prediction for a day that experience several storms. When several storms occur during a single day, the soil moisture level and the corresponding runoff curve number vary from storm to storm [11]. However, SCS-CN methods define a rainfall event as the sum of all rainfall that occurs during one day, and this might lead to underestimation of runoff [12].

\section{Evaluation of sediment load simulation}

The results obtained during calibration periods of sediment load simulation are shown in Figures 6 and 7. The majority of sediment 
Citation: Gull S, Ahangar MA, Dar AM (2017) Prediction of Stream Flow and Sediment Yield of Lolab Watershed Using SWAT Model. Hydrol Current Res 8: 265. doi: 10.4172/2157-7587.1000265

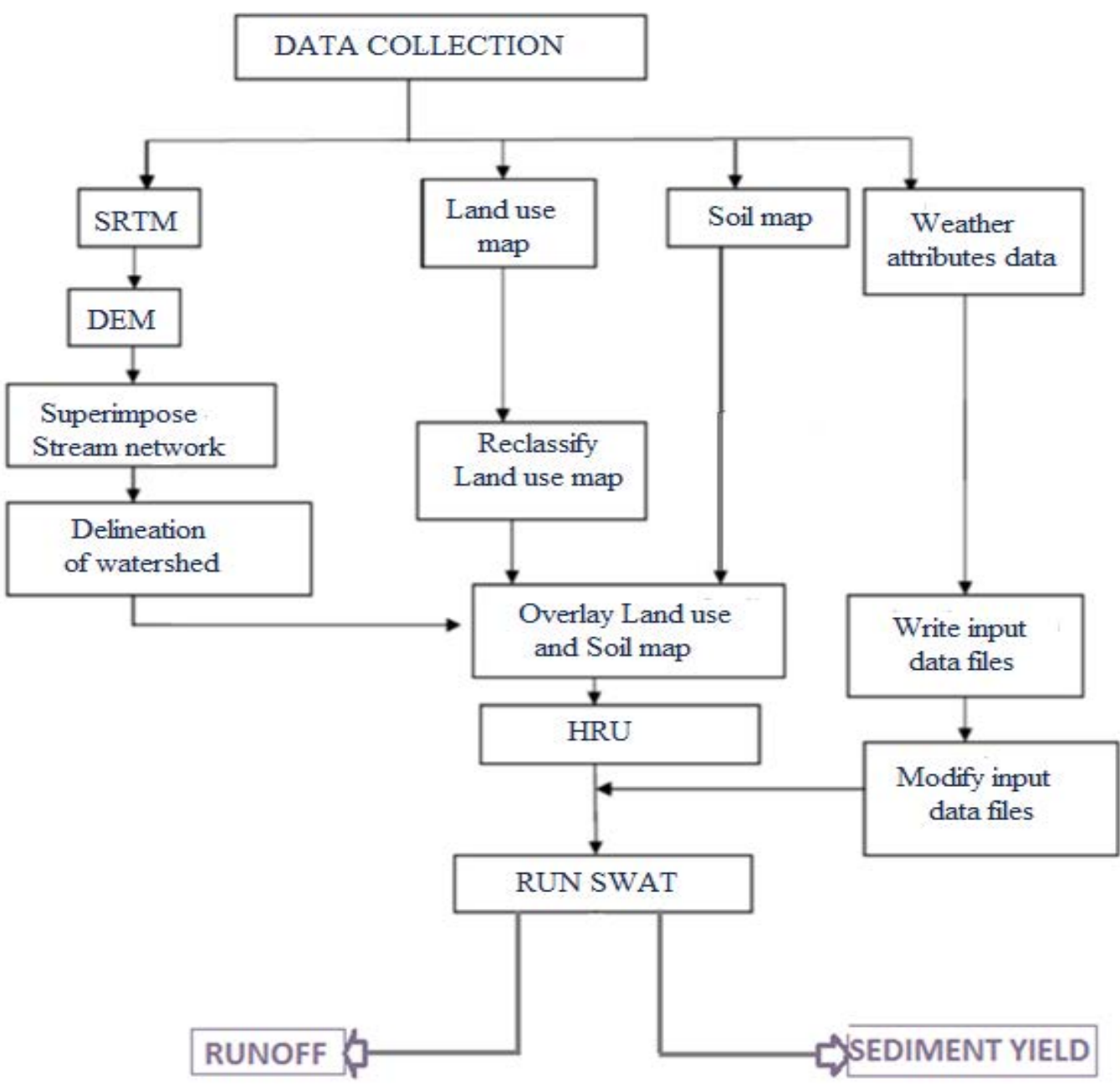

Figure 1: SWAT methodology for simulation of runoff and sediment yield.

\begin{tabular}{|c|c|c|c|c|}
\hline $\begin{array}{l}\text { The most sensitive } \\
\text { parameters }\end{array}$ & Parameter definition & Range & $\begin{array}{l}\text { Ranks of the } \\
\text { parameters }\end{array}$ & Calibrated value \\
\hline $\mathrm{CN} 2$ & Initial SCS CN II value & $\pm 25 \%$ & 1 & $7 \%^{a}$ \\
\hline SOL_AWC & Soil available water capacity (\%) & $\pm 25 \%$ & 2 & $-20 \%{ }^{a}$ \\
\hline SOL_K & Saturated hydraulic conductivity $(\mathrm{mm} / \mathrm{h})$ & $\pm 15 \%$ & 3 & $-13 \%^{a}$ \\
\hline SOL_Z & Depth from soil surface to the bottom of the layer $(\mathrm{mm})$ & 0 to 3000 & 4 & 2400 \\
\hline ESCO & Soil evaporation compensation factor & 0.1 to 1 & 5 & 0.15 \\
\hline ALPHA BF & Base flow alpha factor(days) & 0 to 1 & 6 & 0.7 \\
\hline GWQMN & $\begin{array}{l}\text { Threshold depth of water in a shallow aquifer for return } \\
\text { flow }(\mathrm{mm})\end{array}$ & 0 to 1000 & 7 & 32 \\
\hline SLSUBBSN & Average slope length $(\mathrm{m})$ & 10 to 300 & 8 & $25-228$ (varies by subbasins) \\
\hline EPCO & Plant evaporation compensation factor & 0.01 to 1 & 9 & 0.38 \\
\hline $\mathrm{CH} \_\mathrm{K} 2$ & Channel effective hydraulic conductivity $(\mathrm{mm} / \mathrm{h})$ & 0 to 500 & 10 & 31 \\
\hline
\end{tabular}

Table 1: Sensitive parameters for stream flow simulation and calibrated values.

\begin{tabular}{|c|c|c|c|}
\hline The most sensitive parameters & Parameter definition & Range & Ranks of the parameters \\
\hline SPCON & Lalibrated value \\
\hline CH_EROD & Channel erodibility factor & $0.0001-0.01$ & 0.008 \\
\hline SPEXP & Exponent parameter for sediment re-entrainment & $01-$-Feb & 2 \\
\hline CH_COV & Channel cover factor & 0.55 & 3 \\
\hline
\end{tabular}

Table 2: Sensitive parameters for sediment load simulation and calibrated values. 


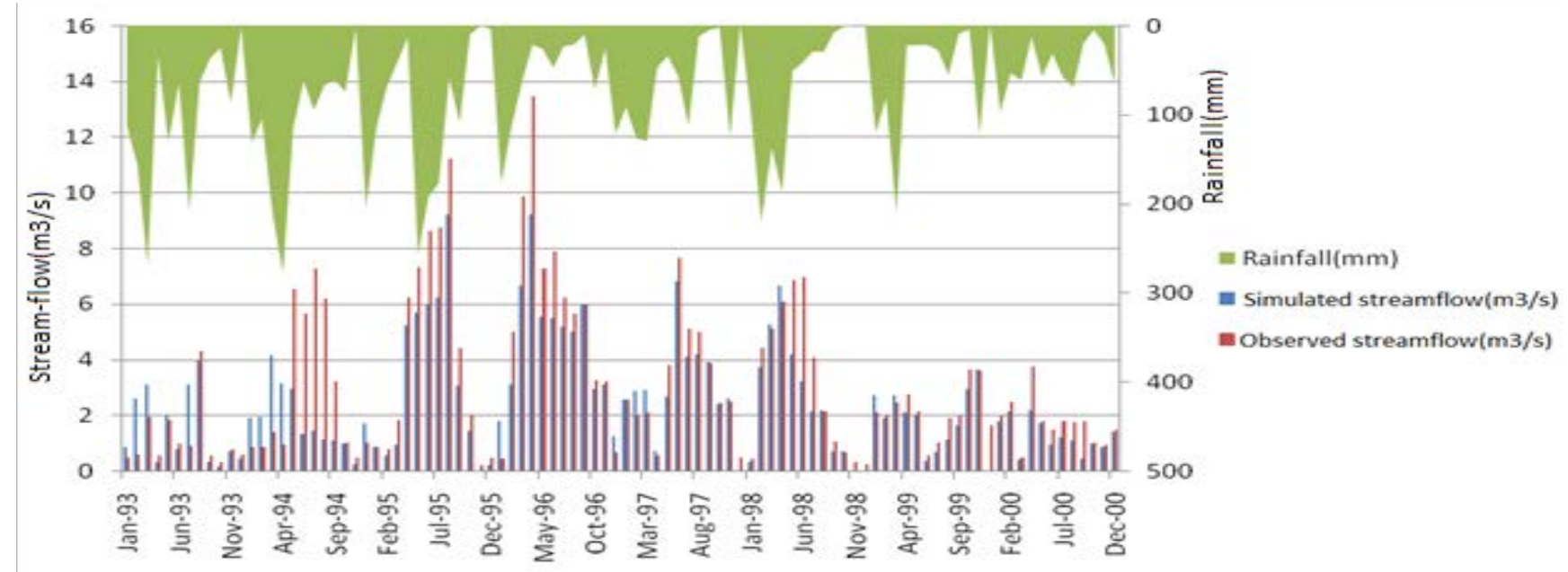

Figure 2: Bar chart showing monthly observed and simulated stream flow of Lolab watershed during calibration Period.

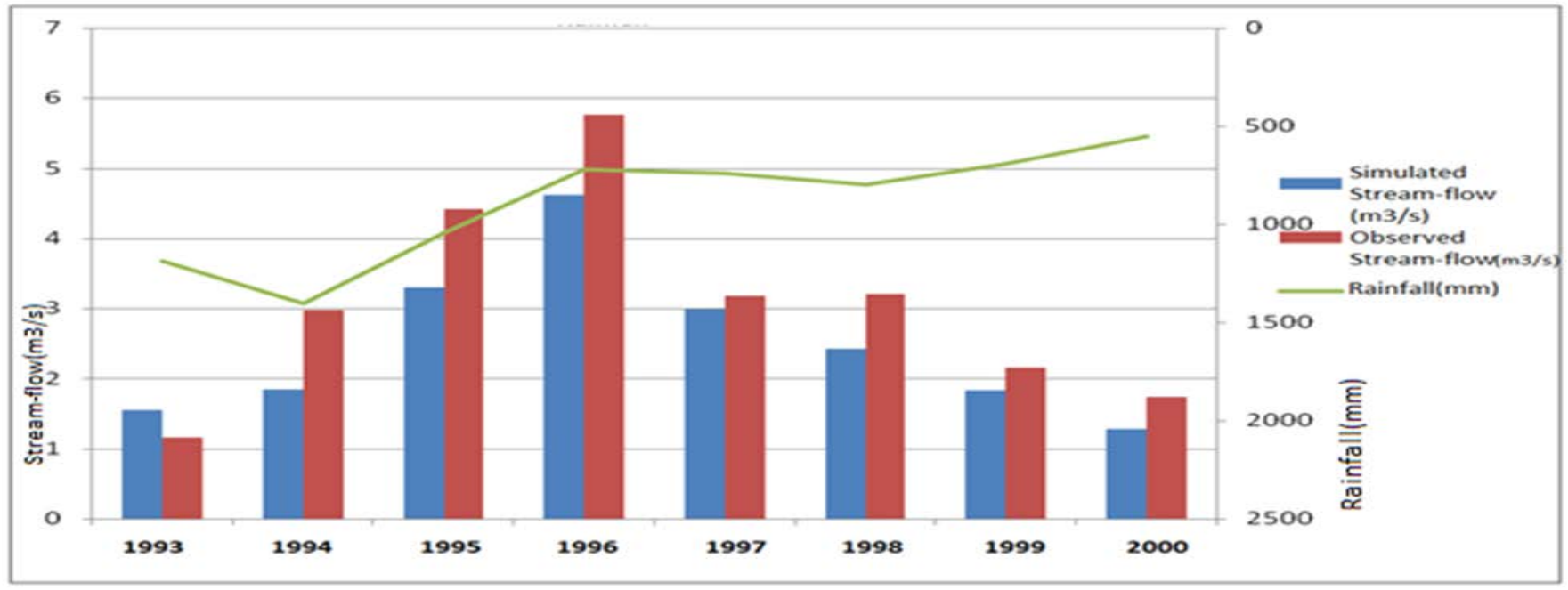

Figure 3: Bar chart showing yearly observed and simulated stream flow of Lolab watershed during calibration Period.

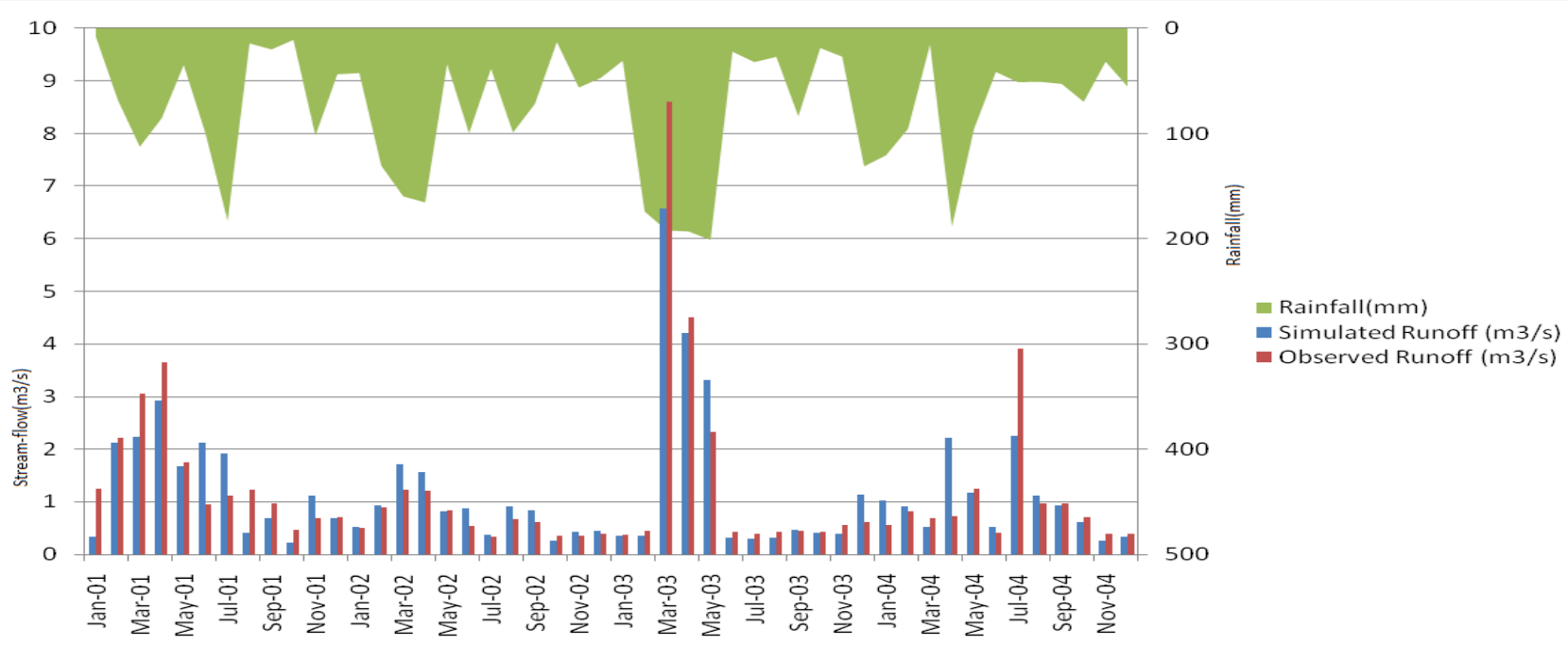

Figure 4: Bar chart showing monthly observed and simulated stream flow of Lolab watershed during validation Period. 
Citation: Gull S, Ahangar MA, Dar AM (2017) Prediction of Stream Flow and Sediment Yield of Lolab Watershed Using SWAT Model. Hydrol Current Res 8: 265. doi: 10.4172/2157-7587.1000265

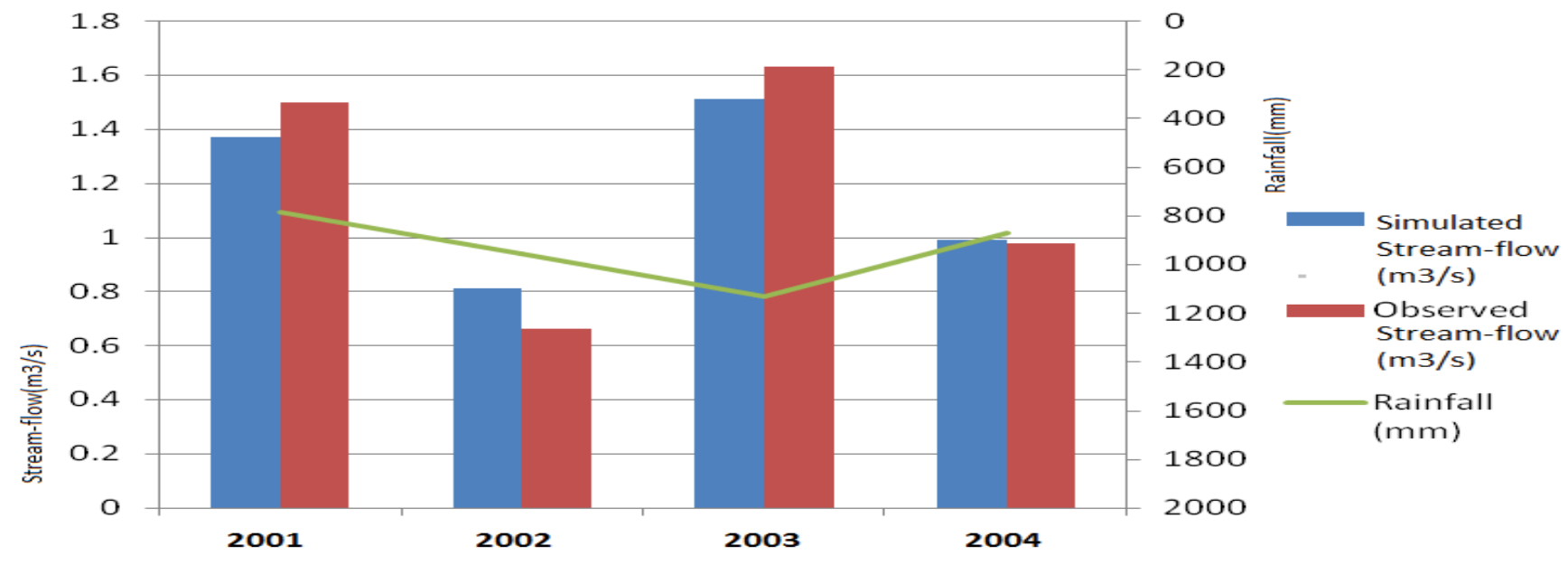

Figure 5: Bar chart showing yearly observed and simulated stream flow of Lolab watershed during validation Period.

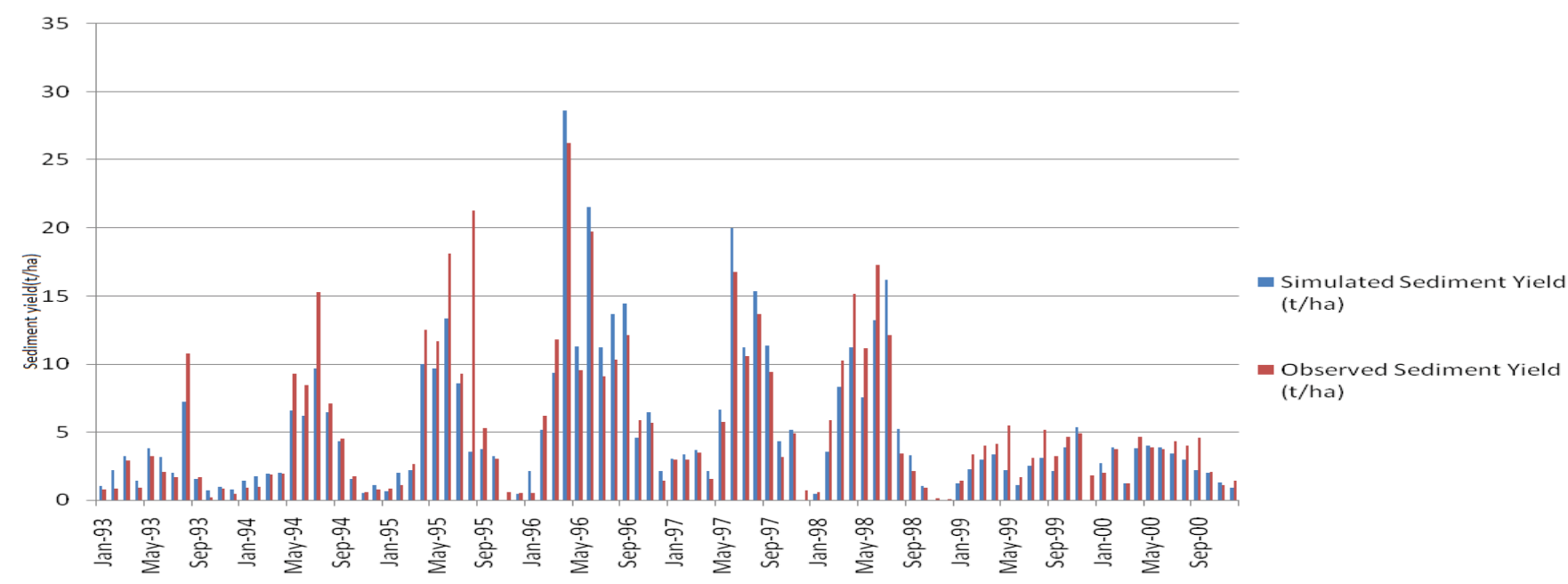

Figure 6: Bar chart showing monthly observed and simulated sediment yield of Lolab watershed during calibration Period.

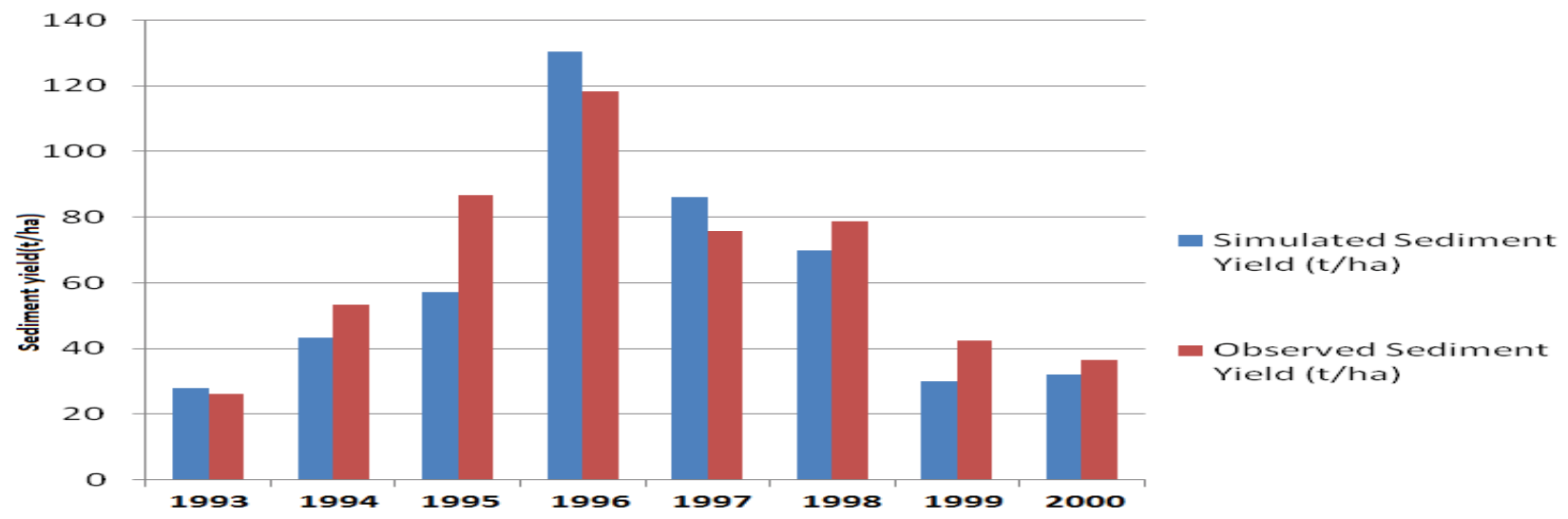

Figure 7: Bar chart showing yearly observed and simulated sediment yield of Lolab watershed during calibration Period. 
Citation: Gull S, Ahangar MA, Dar AM (2017) Prediction of Stream Flow and Sediment Yield of Lolab Watershed Using SWAT Model. Hydrol Current Res 8: 265. doi: 10.4172/2157-7587.1000265

Page 7 of 9

transport occurs during high-flow events; therefore, capturing these events accurately is vital to model calibration [13]. The monthly and yearly $\mathrm{R}^{2}$ and the $\mathrm{N}_{\mathrm{SE}}$ demonstrated that the correlation and agreement between them was acceptable, shown in Table 4. For validation period, the observed and simulated sediment loads during 2001-2004 are shown in Figures 8 and 9. Although the validation period showed a better match than the calibration period, the SWAT tended to underestimate many of sediment loads in both calibration as well as validation periods.

\section{Sediment distribution}

The spatial variability of sedimentation rates was identified and based on which the potential area of intervention was identified. The average annual yield of sedimentation for each sub-basin was used to generate sediment source map shown in Figure 10. The study showed that Sub-basins 24, 25, 28 and 38 of Lolab watershed at the existing condition generates maximum annual average sediment yields of $139.54 \mathrm{t} / \mathrm{ha}, 132.98 \mathrm{t} / \mathrm{ha}, 138.06 \mathrm{t} / \mathrm{ha}, 129.23 \mathrm{t} / \mathrm{ha}$ respectively. This was attributed due to the topographic slope of these sub-basins. It was a land with more than $42.72 \%$ of which has a slope greater than 23 degrees.

\section{Conclusion}

Although the problem of soil erosion is recognized from gross erosion estimates and field observations, quantitative information and data are required at micro watershed level to develop alternative watershed management plans and for decision making. In this study, attempts were made to characterize the Lolab watershed in terms of stream flow and sediment yield and identification of potential sediment source areas. In this study the performance of SWAT model was evaluated using Standard calibration and validation statistics. A good agreement between monthly and yearly measured and simulated stream-flow was demonstrated by correlation coefficients Viz. Monthly $\mathrm{R}^{2}=0.74$ Yearly $\mathrm{R}^{2}=0.90$ and Nash-Sutcliffe model efficiency with Monthly $\mathrm{E}_{\mathrm{NS}}=0.68$ and Yearly $\mathrm{E}_{\mathrm{Ns}}=0.68$ for calibration period while as Monthly $\mathrm{R}^{2}=0.85$, Yearly $\mathrm{R}^{2}=0.99$ and Monthly $\mathrm{E}_{\mathrm{NS}}=0.83$, Yearly $\mathrm{E}_{\mathrm{NS}}=0.91$ for validation period. In simulating sediment yield, the monthly and yearly correlation coefficients i.e., $\mathrm{R}^{2}$ for calibration period were 0.80 and 0.86 respectively while as the monthly and yearly Nash-Sutcliffe model efficiency coefficients i.e., $\mathrm{E}_{\mathrm{NS}}$ were 0.79 and 0.78 respectively. The values of monthly and yearly correlation coefficients i.e., $\mathrm{R}^{2}$ for validation period were 0.88 and 0.83 respectively while as

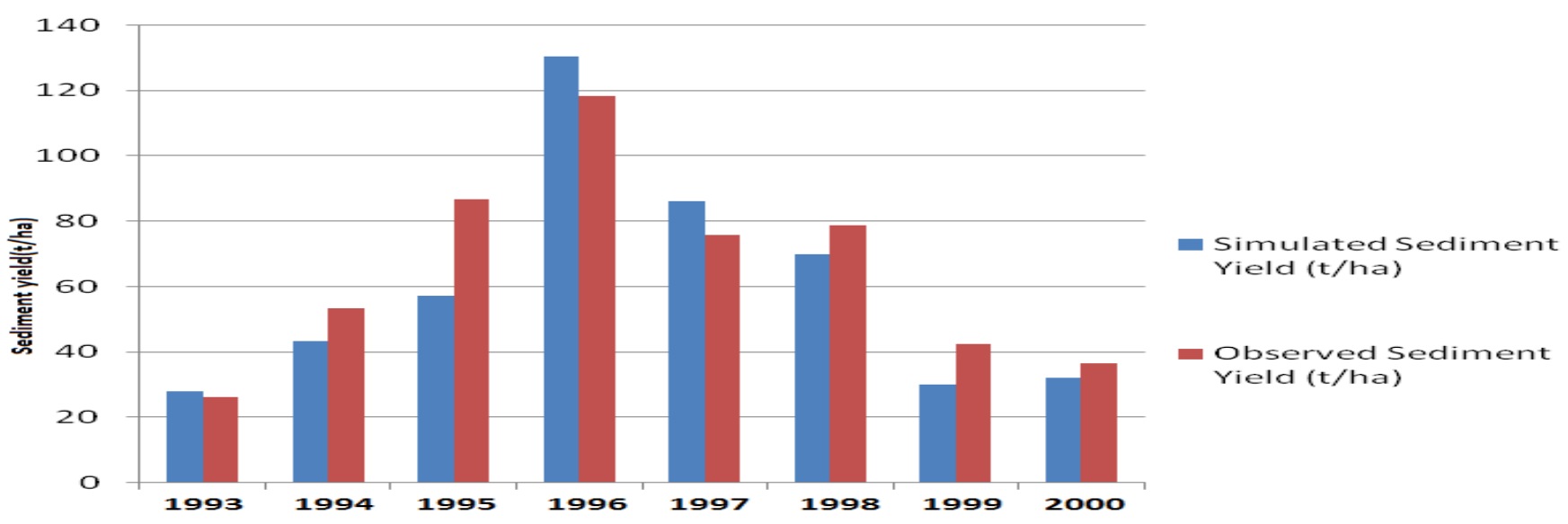

Figure 8: Bar chart showing monthly observed and simulated sediment yield of Lolab watershed during validation Period.

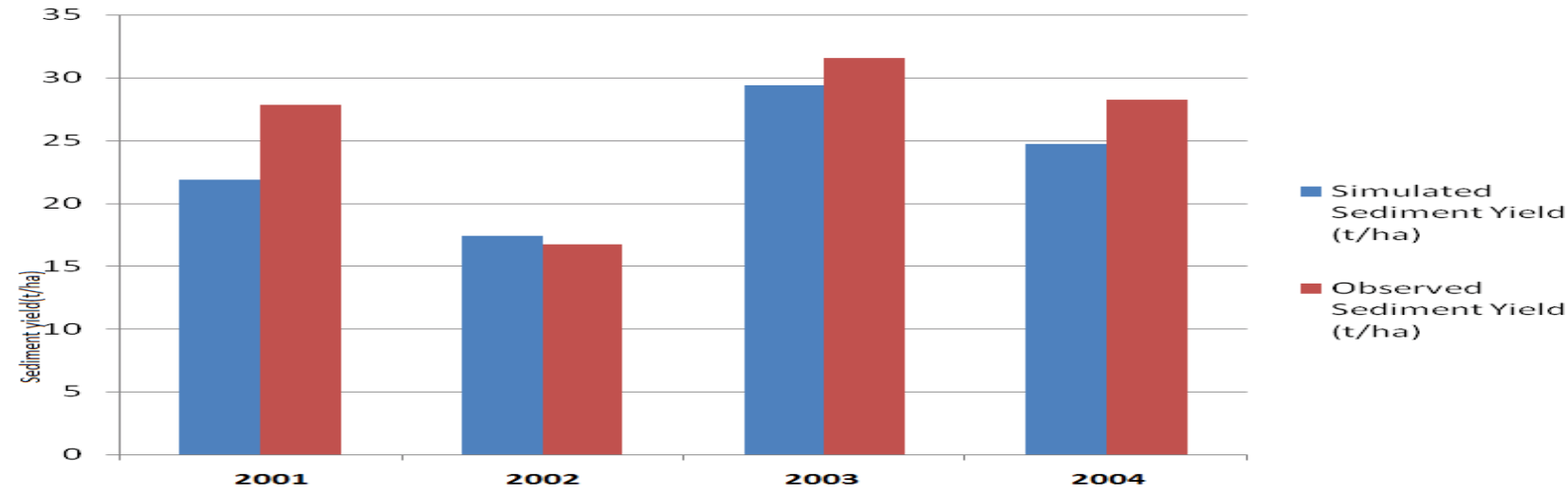

Figure 9: Bar chart showing yearly observed and simulated sediment yield of Lolab watershed during validation Period. 
Citation: Gull S, Ahangar MA, Dar AM (2017) Prediction of Stream Flow and Sediment Yield of Lolab Watershed Using SWAT Model. Hydrol Current Res 8: 265. doi: 10.4172/2157-7587.1000265

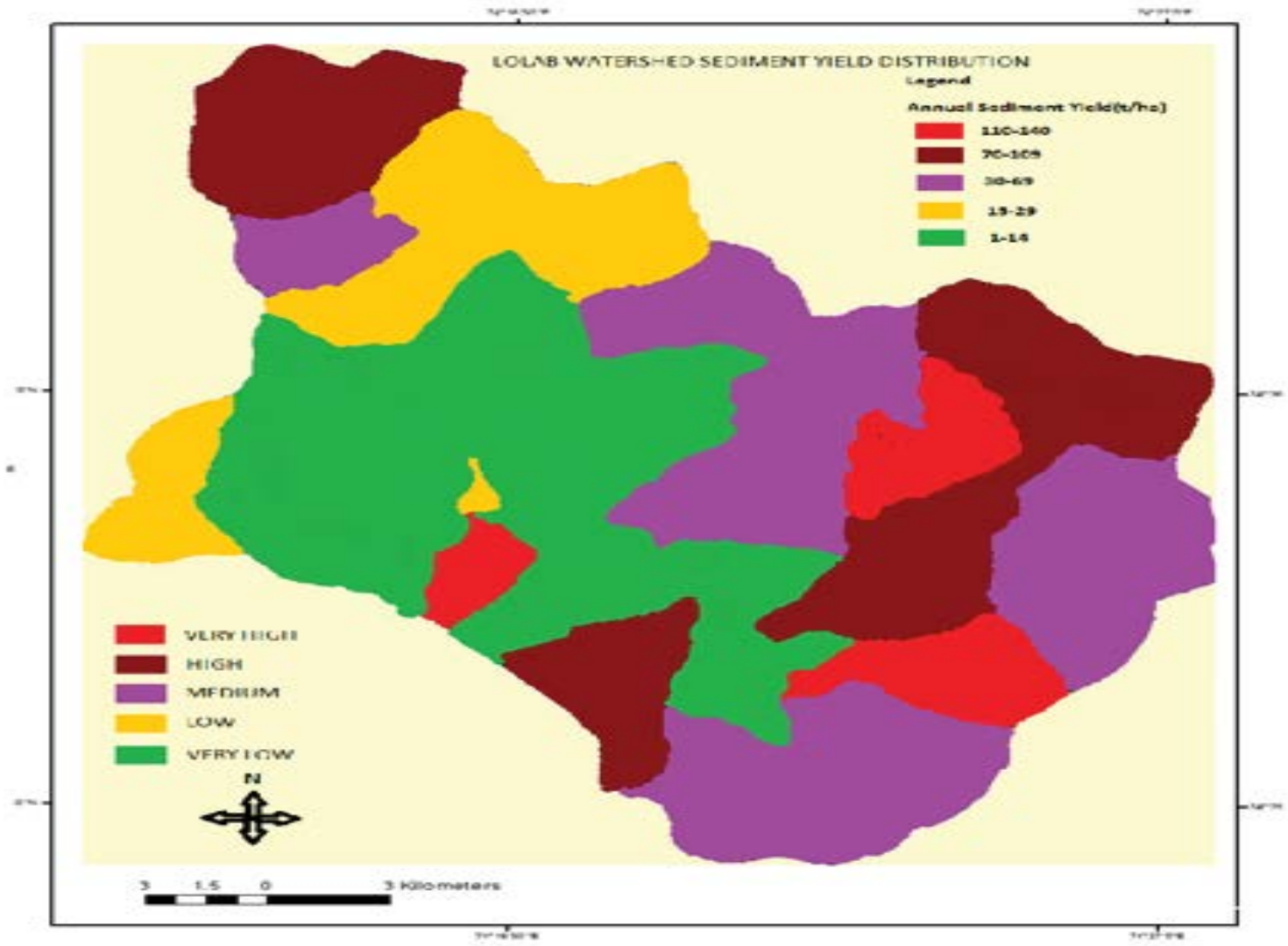

Figure 10: Shows the spatial variability of sedimentation rate.

\begin{tabular}{|l|c|c|c|c|}
\hline \multirow{2}{*}{} & \multicolumn{2}{|c|}{ Nash-Sutcliffe model efficiency $\mathbf{( N}_{\mathrm{SE}}$ ) } & \multicolumn{2}{|c|}{ Coefficient of Determination $\mathbf{(}_{\mathbf{2}} \mathbf{)}$} \\
\cline { 2 - 5 } & Monthly & Yearly & Monthly & Yearly \\
\hline CAL & 0.68 & 0.68 & 0.74 & 0.9 \\
\hline VAL & 0.83 & 0.91 & 0.85 & 0.99 \\
\hline
\end{tabular}

Table 3: Model efficiencies for stream flows during calibration and validation periods.

\begin{tabular}{|c|c|c|c|c|}
\hline \multirow{2}{*}{} & \multicolumn{2}{|c|}{$\left.\begin{array}{c}\text { Nash-Sutcliffe model } \\
\text { efficiency }\end{array} \mathbf{( N}_{\text {sE }}\right)$} & \multicolumn{2}{c|}{$\begin{array}{c}\text { Coefficient of Determination } \\
\left(\mathbf{R}_{\mathbf{2}}\right)\end{array}$} \\
\cline { 2 - 5 } & Monthly & Yearly & Monthly & Yearly \\
\hline CAL & 0.79 & 0.78 & 0.80 & 0.86 \\
\hline VAL & 0.86 & 0.58 & 0.88 & 0.83 \\
\hline
\end{tabular}

Table 4: Model efficiencies for Sediment yield during calibration and validation periods.

the monthly and yearly Nash-Sutcliffe model efficiency coefficients i.e., $\mathrm{E}_{\mathrm{NS}}$ were 0.86 and 0.58 respectively. A good performance of the model in the Validation period indicates that the fitted parameters during calibration period can be taken as a representative set of parameters for Lolab watershed and further simulation and evaluation of alternative scenario analysis can be carried out for other periods using the SWAT model. The SWAT model prediction verified that the Lolab watershed is highly erosion potential area contributing high sediment yield exceeding the tolerance limit (soil formation rate) in the study area.

In general, the methodology presented in this paper can be used in other watersheds, and the results are instructive for further use of SWAT in evaluating different management scenarios in hilly-gullied regions of Kashmir. Sub-basin no's 24, 25, 28, 38 of Lolab watershed at the existing condition generates a maximum annual average sediment yield, this can be reduced by using sediment yield intervention strategies such as land slope stabilization, construction bench terraces, changing the land use of steep area and afforestation.

\section{Acknowledgements}

We are thankful to the Department Earth Sciences, Kashmir University and Department of Irrigation and Flood Control, Jammu and Kashmir for providing the moral support as well as necessary data. We are also greatly thankful to the National Institute of Technology, Srinagar for providing us the lab facilities and our regards also go to the Meteorological Department, Kashmir as well as SKUAST-K for a moral support.

\section{References}

1. Rajora R (1998) Integrated watershed management. Chapter 24. Rawat Publications, Jaipur, India.

2. Food and Agriculture Organization (FAO) (1985) Guidelines for economic appraisal of watershed management projects. In: Gregersen HM, Brooks KN, Dixon JA, Hamilton LS. F'AO Conservation Guide No 16, Rome, Italy.

3. Pulle AA (1988) African Rice (Oryza glaberimma Stued.): Lost crop of the enslaved Africans Discovered in Suriname. An article published by Tinde Van Andel, Mar 5, 2010.

4. Arnold JG, Srinivasan R, Muttiah RS, Williams JR (1998) Large area hydrologic modeling and assessment - Part 1: Model development. Journal of the American Water Resources Association 34: 73-89.

5. Setegn SG, Srinivasan R, Dargahi B (2008) Hydrological Modeling in the Lake Tana Basin, Ethiopia Using SWAT Model. The Open Hydrology Journal 2: 49-62.

6. Fontaine TA, Cruickshank TS, Arnold JG, Hotchkiss RH (2002) Development of a snowfall-snowmelt routine for mountainous terrain for the soil water assessment tool (SWAT). Journal of Hydrology 262: 209-223. 
Citation: Gull S, Ahangar MA, Dar AM (2017) Prediction of Stream Flow and Sediment Yield of Lolab Watershed Using SWAT Model. Hydrol Current Res 8: 265. doi: 10.4172/2157-7587.1000265

Page 9 of 9

7. Van Griensven A (2005) Sensitivity, auto-calibration, uncertainty and model evaluation in SWAT2005.

8. Van Griensven A, Green CH (2007) Auto-calibration in Hydrological Modeling: Using SWAT2005 in small-scale watersheds. Environmental Modeling \& Software 23: 422-434.

9. Eckhardt K, Arnold JG (2001) Automatic calibration of a distributed catchment model. Journal of Hydrology 251: 103-109.

10. Kannan N, White SM, Worrall F, Whelan MJ (2007) Sensitivity analysis and identification of the best evapotranspiration and runoff options for hydrological modelling in SWAT-2000. Journal of Hydrology 332: 456-466.

11. Kim NW, Lee J (2008) Temporally weighted average curve number method for daily runoff simulation. Hydrological Processes 22: 4936-4948.

12. Chow VT, Maidment DR, Mays LW (1988) Applied Hydrology. McGraw Hill, New York, USA, pp: 47-61.

13. Benaman J, Shoemaker CA (2005) An analysis of high-flow sediment event data for evaluating model performance. Hydrological Processes 19: 605-620. 